\title{
AVALIAÇÃO DO DESEMPENHO TÉRMICO E DO CONFORTO AMBIENTAL EM HABITAÇÃO UNIFAMILIAR DE INTERESSE SOCIAL
}

\author{
CARVALHO, Isabelle M (1); \\ MENEZES, João Victor (2); \\ NAZARETH, Samuel Bertrand (3); \\ (1) Universidade de Fortaleza, Graduanda em Arquitetura e Urbanismo \\ e-mail: mendoncaisabelle@gmail.com \\ Universidade de Fortaleza, Bacharel em Arquitetura e Urbanismo \\ e-mail: arq.joaovictor@outlook.com \\ (3) Universidade de Fortaleza, Bacharel em Arquitetura e Urbanismo, \\ e-mail: bmnsamuel@gmail.com
}

\begin{abstract}
RESUMO
As pessoas têm gasto a maior parte do tempo dentro de ambientes construidos, qualquer que seja a tipologia da edificação. Este costume, consolidado em nossa sociedade, influencia de modo direto o conforto e o consumo de energia. Desta forma, avaliar este fator é de fundamental importância, de modo que se possa estabelecer padrões de desempenho ambientais. Essa avaliação, objeto de estudo deste artigo, permite, ainda, compreender a capacidade de adaptação e as limitacões do corpo humano, na vivência do conforto em seu ambiente rotineiro.
\end{abstract}

Palavras chave: Conforto Ambiental; Desempenho térmico; Habitacão de interesse social.

\begin{abstract}
People spend most of their time in built environments, whatever is the building typology. This attitude is already fully consolidated in our society, and influences directly in some aspects of the building environment, such as comfort and energy consumption. Assessing this aspect, is a key to establish environmental performance standards. This paper aims to understand what the human body is able to withstand, as well as how people are willing to make behavioral changes, considering their experience inside their routine environment.
\end{abstract}

Keywords: Environmental comfort; Thermal performance; Social housing. 


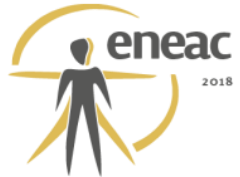

\section{INTRODUÇÃO}

Um dos aspectos fundamentais da arquitetura é proporcionar conforto aos ocupantes de ambientes internos. A ASHRAE (2004) define conforto térmico como a condição mental que expressa satisfação com o ambiente térmico. Tal condição depende da interação de quatro fatores objetivos: a temperatura, a umidade e a velocidade do ar e a temperatura das superfícies que o cercam. A adoção de limites de temperatura e umidade do ar nas quais o corpo humano está em equilíbrio hidrotérmico delimita um intervalo denominado de zona de conforto.

É sabido que o consumo de energia em edifícios depende dos meios utilizados para controlar as condições ambientais internas. Muito embora o projeto, a construção ou a readequação de edificações ecologicamente conscientes constitua uma necessidade cada vez mais evidente no cenário atual, a economia de energia não deve condenar as condições de conforto e a saúde dos ocupantes (OLESEN, 2007).

\section{METODOLOGIA}

A concepção deste modelo de casa de interesse social foi feita primeiramente no software Autocad, assim, produzindo cortes, fachadas e uma planta baixa para então ser exportada com sua unidade em metros para o programa de modelagem 3D Sketchup, onde foi feito o modelo completo com aberturas vazadas em suas esquadrias sem nenhum aparato de proteção solar e foi feito os beirais de 50 centímetros propositadamente pequenos para poder haver uma maquete para comparação de dados.

Após o processo de modelagem, o produto desta etapa é exportado com uma extensão DXF (Drawing Exchange Format) e importado pelo programa Autodesk Ecotect. Neste programa, é feita a modelagem dos aparatos de proteção solar, e a partir deles é produzida pelo próprio software as máscaras de insolação das aberturas; ainda no Ecotect, é realizada também a simulação de iluminação natural (com assistência do plug-in radiance) a 80 centímetros do chão no dia do solstício de inverno (vinte e dois de dezembro) para aferir se estava aceitável, com cerca de 300 lux no mínimo.

Após de toda modelagem, tanto do objeto de estudo quanto do entorno fictício, o modelo é exportado para um quarto programa, também da Autodesk, FlowDesign. Assim, apos a importação, o modelo é alinhado com o leste, a qual é o inlet deste modelo, a velocidade adotada para aferir a pressão realizada no objeto de estudo é 10 metros por segundo, em um segundo momento, antes da simulação, é realizado a modelagem do tubo de vento em relação ao modelo, onde as distâncias são relacionadas a partir da maior edificação do modelo, levando em consideração cinco vezes a distância da maior edificação a partir da poligonal da área em relação ao inlet, 15 vezes pela mesma relação o outlet e 5 vezes as demais distâncias, sendo assim, produzindo um modelo pronto para simulação.

Por último, foi utilizado o software designbuilder para a simulação das temperaturas, levando em consideração a ventilação natural e nenhum estimulo de ventilação artificial. Sendo assim, uma condição sine qua non para o desenvolvimento da simulação de ventilação, para assim, aferir a pressão e calcular o número de renovações de ar por hora. Após a simulação no software, os dados são levados ao Microsoft Excel, para o desenvolvimento de tabelas que levam em consideração a temperatura operativa e de ganhos por radiação, sendo possível calcular as horas de conforto e desconforto. 


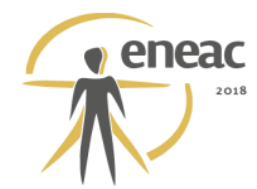

\section{CONTEÚDO}

\subsection{Características construtivas da edificação}

Por ser uma edificação de interesse social e para manter a simulação simples de ser realizada, os materiais aplicados na edificação foram simples. Constitui-se basicamente de paredes internas e externas de tijolo 8 furos quadrado de 14 centímetros, laje de concreto e cerâmica $15 \mathrm{~cm}$ e telhas de barro sem forro como a imagem abaixo ilustra.

Figura 1 - Modelagem Designbuilder

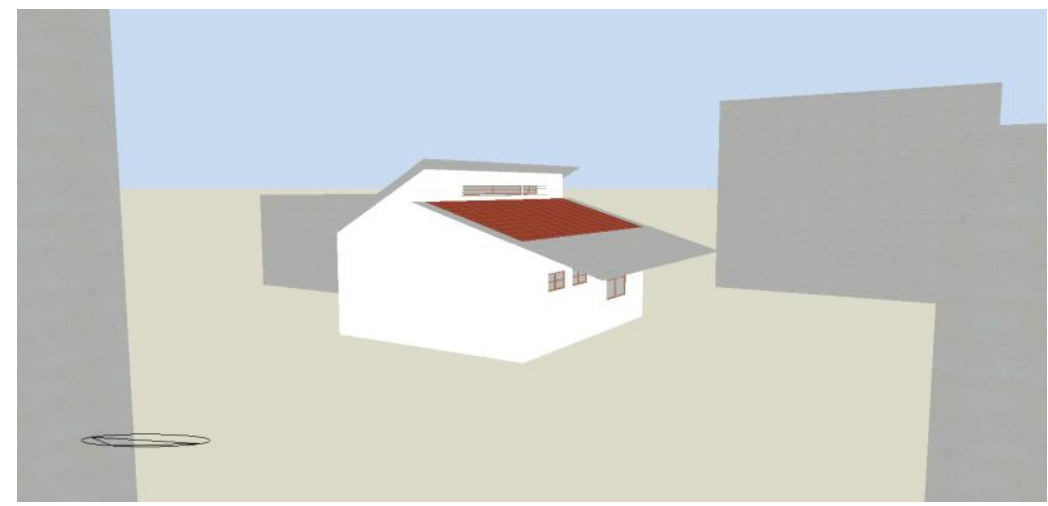

Fonte: Acervo do autor

O programa também possui a funcionalidade de escolher uma rotina de permanência nos cômodos, bem como o tempo que é utilizado de iluminação no mesmo durante um ano tipo. Foi suposto que seria utilizado luz artificial das 6 às 7 horas da manhã e das 18 às 22 horas. E enquanto a permanência foi escolhida 2 tipos de cômodos, a sala e os quartos. Os quartos seriam utilizados das 21 às 6 horas da manhã e das 13 às 14 horas. E a sala seria nos tempos as quais as pessoas não estejam no quarto.

Figura 2: Rotina Quarto - Designbuilding

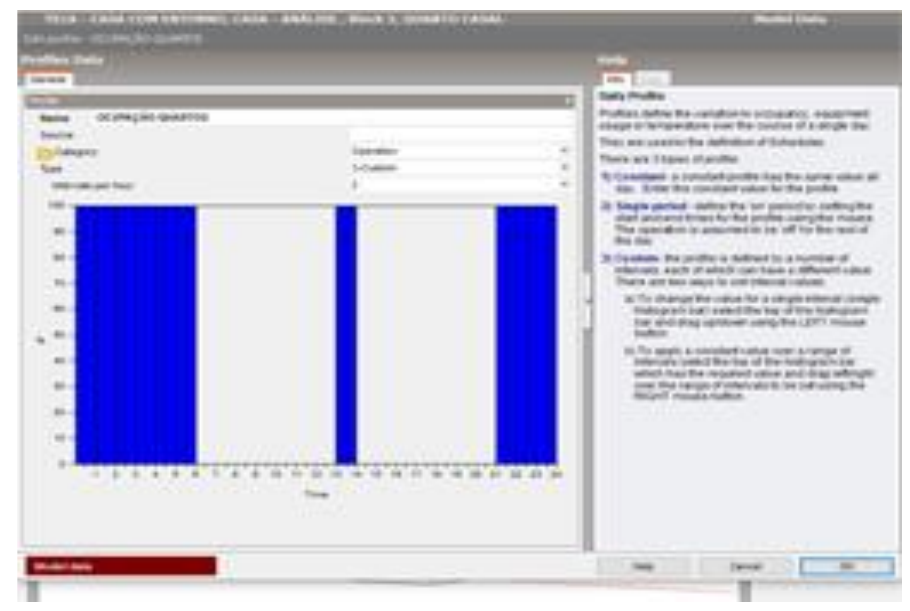

Fonte: acervo do autor.

\subsection{Paredes (Valor de U)}

Cálculo realizado

Resistência - Parede Vertical $=0,17$

- Parede Horizontal (Fluxo de dentro para fora) $=0,14$ 
- Parede Horizontal Horizontal (Fluxo de dentro para fora) $=0,22$

Resistência do tijolo:

\begin{tabular}{|c|c|c|}
\hline \multicolumn{2}{|l|}{ Seção 01} & Seção 02 \\
\hline $\begin{array}{l}\mathbf{A} 1=0,01 \quad \mathrm{X} \\
\mathbf{A} 1=0,0019 \mathrm{~m}^{2}\end{array}$ & 0,19 & $\begin{array}{l}\mathbf{A} 2=0,035 \\
\text { A2 }=0,00665 \mathrm{~m}^{2}\end{array}$ \\
\hline $\begin{array}{l}\mathbf{R} 1=\frac{e \text { cerâmica }}{\lambda \text { cerâmica }}= \\
0,1\end{array}$ & $\frac{0,09}{0,90}=$ & $\begin{array}{l}\text { R2 } \\
=\frac{\text { ce cerâmica }}{\lambda \text { cerâmica }}+\text { RAR }+\frac{\theta \text { cerâmica }}{\lambda \text { cerâmica }}+\text { RAR }+\frac{\theta \text { cerâmica }}{\lambda \text { cerầmica }}+\text { RAR } \\
\text { R2 }=\frac{0,01}{0,90}+0,16+\frac{0,01}{0,90}+16+\frac{0,01}{0,90}+16 \\
\mathbf{R} 2=0,3533\end{array}$ \\
\hline RTIJOLO & $=\frac{5 x A 1}{\frac{5 x A 1}{R 1}}$ & $\begin{array}{l}\frac{+4 x A 2}{R 2} \text { RTIJOLO }=\frac{5 x 0,0019+4 x 0,00665}{\frac{5 x 0,0019}{0,1}+\frac{4 x 0,00665}{0,35}} \\
\text { RTIJOLO }=0,212\left(\mathrm{~m}^{2} \mathrm{k}\right) / \mathrm{w}\end{array}$ \\
\hline
\end{tabular}

Resistência da parede:

\begin{tabular}{|c|c|}
\hline Seção 03 & Seção 04 \\
\hline $\begin{array}{lll}\mathbf{A} 3=0,01 & \text { x } & 0,19 \\
\mathbf{A} 3=0,0019 \mathrm{~m}^{2} & & \end{array}$ & $\begin{array}{l}\text { A4 }=0,19 \quad \mathrm{x} \\
\mathbf{A 2}=0,036 \mathrm{~m}^{2}\end{array}$ \\
\hline $\begin{array}{l}\mathbf{R} 3=\frac{\text { e reboco }}{\lambda \text { reboco }}+\frac{\text { argamassa }}{\lambda \text { argamassa }}+\frac{\text { ereboco }}{\lambda \text { reboco }} \\
\text { R3 }=\frac{0,02}{1,15}+\frac{0,09}{1,15}+\frac{0,02}{1,15} \\
\text { R3 }=0,113\end{array}$ & $\begin{array}{l}\mathbf{R 4}=\frac{\theta \text { reboco }}{\lambda \text { reboco }}+\text { RTIJOLO }+\frac{\theta \text { reboco }}{\lambda \text { reboco }} \\
\mathbf{R} 2=\frac{0,02}{1,15}+0,212+\frac{0,02}{1,15} \\
\mathbf{R} 2=0,2467\end{array}$ \\
\hline RPAREDE $=\frac{A 3+A 3}{\frac{A 3}{R 3}+\frac{A 3}{R 4}} \quad \mathrm{RP}$ & AREDE $=\frac{0,0019+0,036}{\frac{0,0019}{0,113}+\frac{0,036}{0,2467}}$ \\
\hline RPAREDE $=0,2328$ & $\begin{array}{l}+0,17=0,40\left(\mathrm{~m}^{2} \mathbf{k}\right) / \mathbf{w} \\
\frac{1}{0,40}\end{array}$ \\
\hline
\end{tabular}




\subsection{O atendimento à NBR 15.575}

A edificação está situada na cidade de Fortaleza, classificada na NBR 15.220 na zona bioclimática 8.

Figura 3 - Tabela da NBR 15220.

Tabela 14 - Transmitância térmica de paredes externas

\begin{tabular}{|c|c|c|}
\hline \multicolumn{3}{|c|}{ Transmitância Térmica U } \\
\hline \multicolumn{3}{|c|}{$\mathrm{W} / \mathrm{m}^{2} . \mathrm{K}$} \\
\hline Zonas 1 e 2 & \multicolumn{2}{|c|}{ Zonas $3,4,5,6,7$ e 8} \\
\hline \multirow[t]{2}{*}{$U \leq 2,5$} & $\alpha^{a} \leq 0,6$ & $\alpha^{a}>0,6$ \\
\hline & $U \leq 3,7$ & $U \leq 2,5$ \\
\hline
\end{tabular}

Fonte: NBR 15220.

$O$ valor da resistência $U$ das paredes de tijolos de 8 furos e $14 \mathrm{~cm}$ da unidade residencial, tanto no cálculo demonstrado neste relatório quanto pelo cálculo do software Design Builder, é menor ou igual ao valor de 2,5 , como descrito na tabela. Isto posto, se enquadram na norma da NBR 15.575.

\subsection{Avaliação das condições de insolação}

O relatório prevê com base em simulações em datas chave, neste caso, nos solstícios de verão e de inverno, as quais demonstram maior e menor, incidência solar respectivamente.

\subsubsection{Solstício de verão, com brises.}

Figura 4: Fachada Oeste e sul às 15 horas

Figura 5: Fachada leste e norte às 9 horas

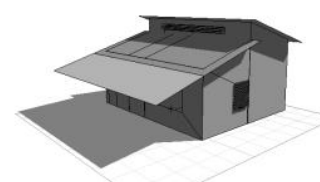

Fonte: Acervo do autor.

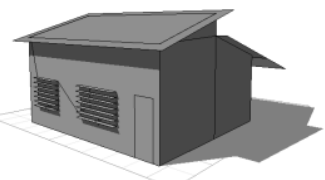

Fonte: Acervo do autor.

\subsubsection{Máscaras solares, com brises.}

Figura 6 - Máscara de sombra das janelas da fachada leste com brises. 


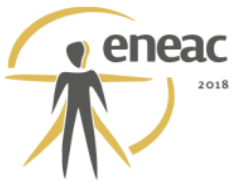
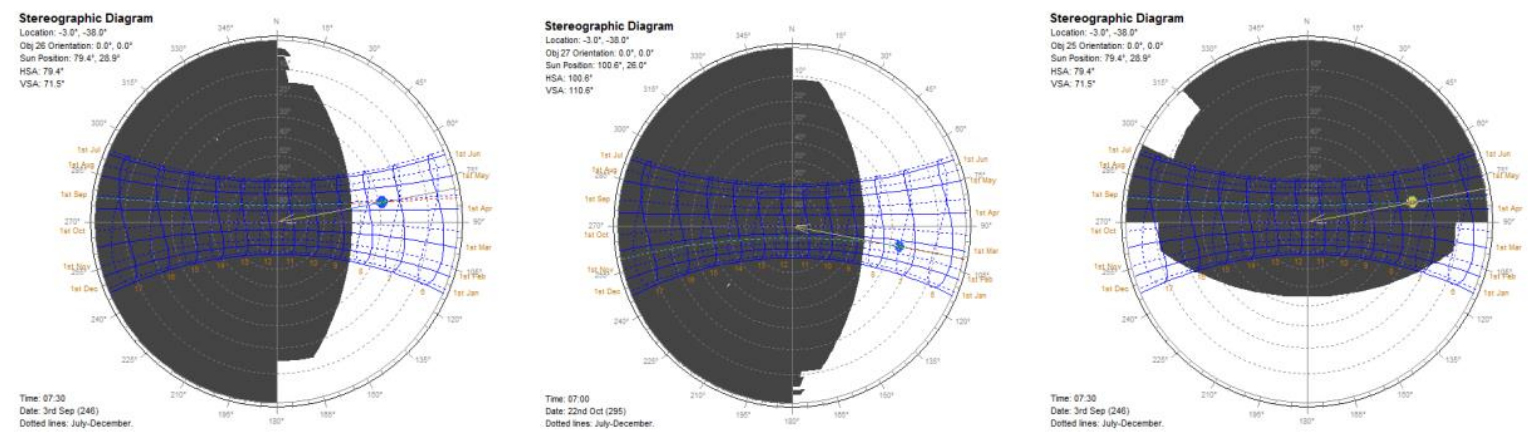

Fonte: Acervo do autor.

Figura 8 - Máscaras de sombra das janelas da fachada oeste com brises.
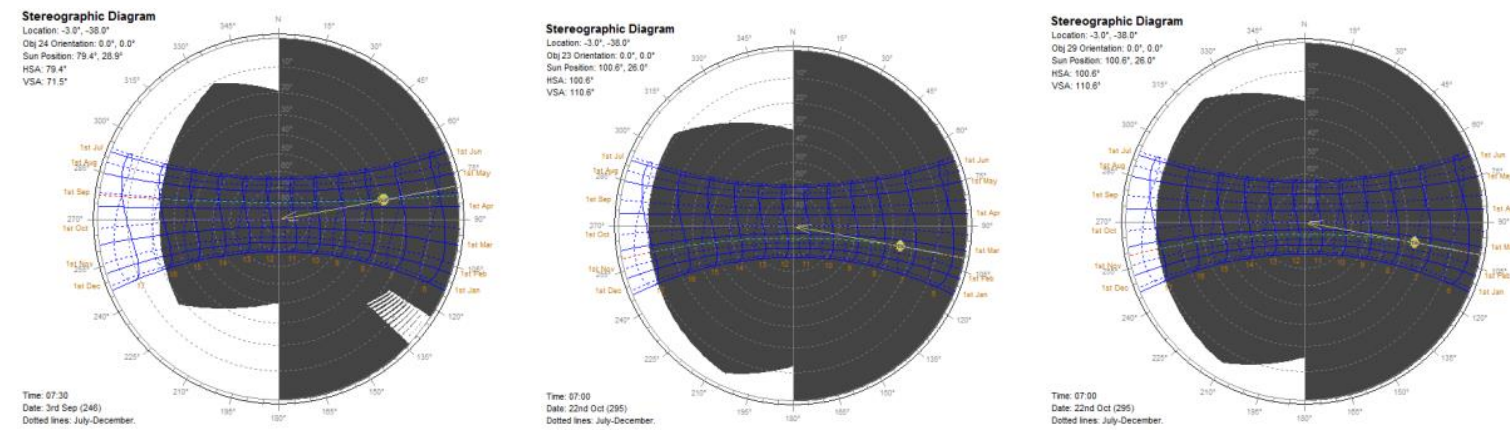

Fonte: Acervo do autor.

\subsection{Avaliação das condições de iluminação natural, com brises.}

Figura 10 - Simulação utilizando o software Ecotect, às 12:00 do dia 22 de dezembro.
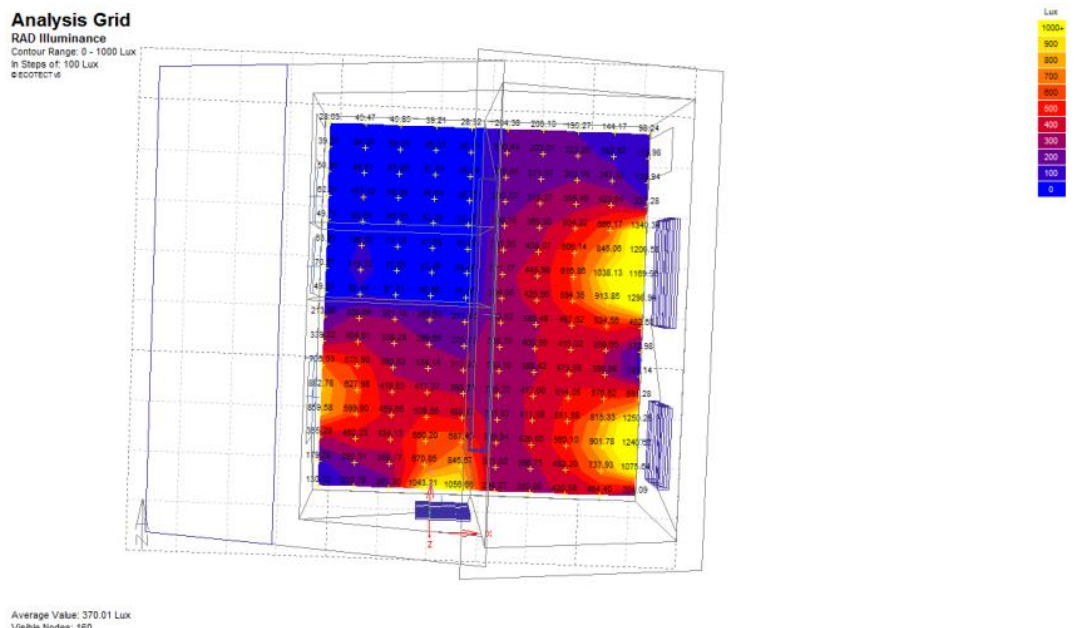

Fonte: Acervo do autor.

\subsubsection{Conclusão da avaliação.}

Para esta simulação dos níveis de iluminância, utilizamos através do plug-in Radiance do software Ecotect, com datas estipuladas a partir dos maiores e menores níveis de iluminância do ano e suas datas críticas, solstício de verão solstício de inverno nos horários de 9horas, 12 horas e 15 horas. 


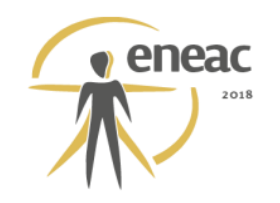

É possível perceber que, a diferença da iluminância nos ambientes (principalmente na sala e nos quartos) foram notoriamente diferentes; a curva de dados nas imagens tem como mais amarelo 1000 lux e mais azul 0 lux. Dentro da justificativa desta simulação, que era perceber se houve a quantidade mínima de 300 lux no plano de trabalho pré-determinado a 80 centímetros, é possível observar que mesmo com a presença dos brises, existe a quantidade necessária para haver a iluminação natural efetiva.

\subsection{Avaliação das condições de ventilação natural.}

Ao passar por uma edificação, o vento gera um campo de velocidades e pressões em suas superfícies externas. Esse campo de pressões nas fachadas depende da direção e intensidade do vento do vento incidente, da densidade do ar, da forma e orientação da superfície e características do entorno tais como topografia e rugosidade do terreno.

Comumente a pressão é positiva a barlavento e negativa a sotavento. Ao criar zonas de alta e baixa pressão nas diferentes faces do edifício, o vento induz o movimento do ar no interior da edificação e esses fluxos dependem essencialmente dos coeficientes de pressão nas fachadas. A determinação dos valores de $\mathrm{Cp}$ nas fachadas e na cobertura de edificações é fundamental para cálculos de taxas de infiltração de ar e ventilação natural.

Utilizou-se o programa Autodesk Flowdesign, para avaliar as condições de ventilação natural no entorno e calcular os dados de coeficientes de pressão sobre as aberturas. Com base nesses dados, foi calculada a vazão de ar possível no ambiente da casa avaliada.

\subsubsection{Avaliação qualitativa.}

Figura 11 - Simulação utilizando o software Flowdesign

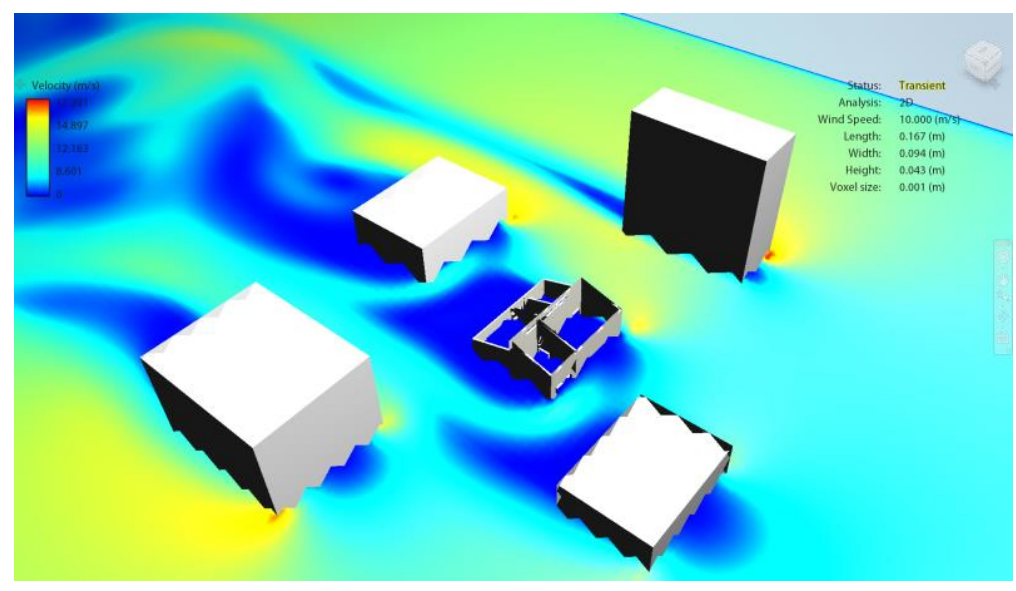

Fonte: Acervo do autor.

\subsubsection{Cálculo de vazão.}

$\phi=C a \cdot A \_0 \cdot v \cdot \sqrt{ }(\Delta \mathrm{Cp}) \quad \mathrm{m}^{3 / \mathrm{s}}$

$\left.\mathrm{v}=\mathrm{V}_{\text {_(ref. }}\right) \cdot \mathrm{k} \cdot \mathrm{za}$

Temos:

$\begin{array}{ll}\text { V_(leste })=4,5 \mathrm{~m} / \mathrm{s} & \mathrm{k}=0,35 \\ \text { A_(entrada })=2,1 \mathrm{~m}^{2} & \mathrm{Z}=1,5 \\ \text { A_(saída })=2,0 \mathrm{~m}^{2} & \mathrm{a}=0,25\end{array}$




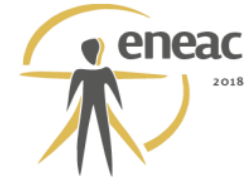

$$
\begin{aligned}
& \text { 『Cp】_(e1 })=0,8 \\
& \text { 『Cp】_(e2 })=0,3 \\
& \text { \Cp】_s1=-0,16 } \\
& \text { 『Cp】_s2 }=-0,24 \\
& \text { 『Cp】_s3 }=-0,24 \\
& \text { 『Cp》_s3 }=-0,24 \\
& \phi=0,65 \cdot \sqrt{ }\left(1 /\left(1 / 2,1^{2}+1 / 2^{2}\right)\right) \cdot((4,5 \times 0,35 \times 1,50,25) \cdot \cos \Theta) \cdot \sqrt{ }(\Delta \mathrm{Cp}) \\
& \phi=0,65 \cdot 1,45 \cdot 1,74 \cdot \sqrt{ }((0,8+0,3)-(-0,16-0,24-0,24-0,24)) \\
& \phi=0,65 \cdot 1,45 \cdot 1,74 \cdot \sqrt{ } 1,98 \\
& \phi=0,65 \cdot 1,45 \cdot 1,74 \cdot 1,4 \\
& \phi=2,29 \mathrm{~m}^{3} / \mathrm{s}
\end{aligned}
$$

Temos vazão/hora como: $\phi=2,29 \mathrm{~m}^{3} / \mathrm{s} \times 3.600 \mathrm{seg}$

$$
\phi=8.244 \mathrm{~m}^{3} / \mathrm{h}
$$

Dessa forma, temos como trocas de ar/hora: $\phi=\left(8.244 \mathrm{~m}^{3} / \mathrm{h}\right) /\left(187,08 \mathrm{v}^{3}\right)=44$ trocas $/$ hora.

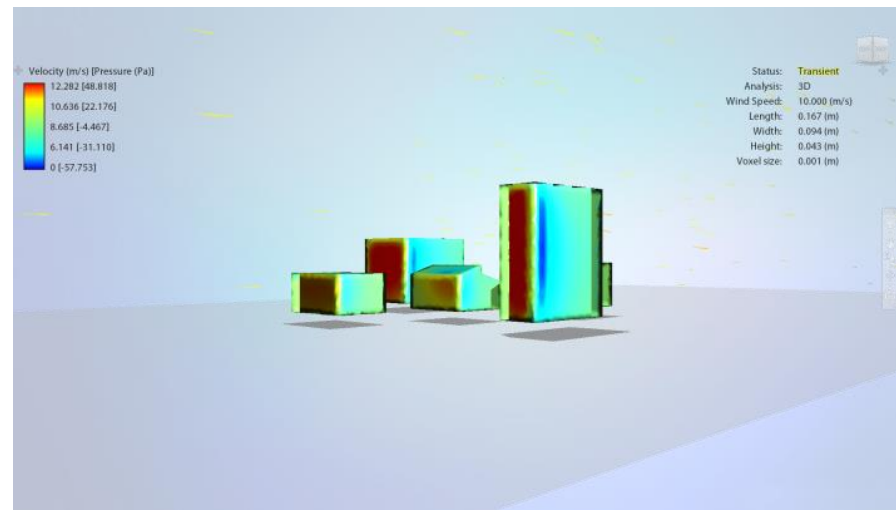

Figura 12: Simulação utilizando o software Flowdesign

Fonte: Acervo do autor.

\subsection{Avaliação do desempenho térmico.}

\subsubsection{Total de ganhos de calor devido à radiação solar.}

O sol constitui a principal fonte de ganhos de calor em edifícios residenciais situados na região tropical. Nessas localidades, a temperatura do ar não é a principal causa de desconforto térmico, mas a temperatura radiante, resultado da incidência solar sobre as diversas superfícies que compõem o ambiente, aquecendo estas que, posteriormente, irradiam energia para o interior do edifício.

A exposição à radiação solar deve, portanto, ser minimizada em climas quentes como forma de reduzir a maior fonte de ganhos de calor e que é capaz de comprometer o conforto térmico no interior dos edifícios residenciais, elevando significativamente o consumo energético para resfriamento.

A verificação do total de ganhos de calor devido à radiação solar constitui, então, parâmetro fundamental para análise das condições de conforto no ambiente interno de edificações. $O$ total anual é, aqui, comparado às situações com e sem elementos de proteção solar. 


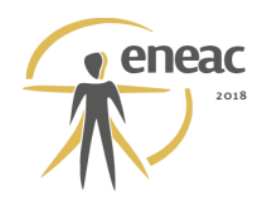

3.6.2 Comparativo entre grau-hora dos ambientes, com brises e sem brises.

Figura 13 - Comparativo entre graus-hora do quarto do casal com e sem brise

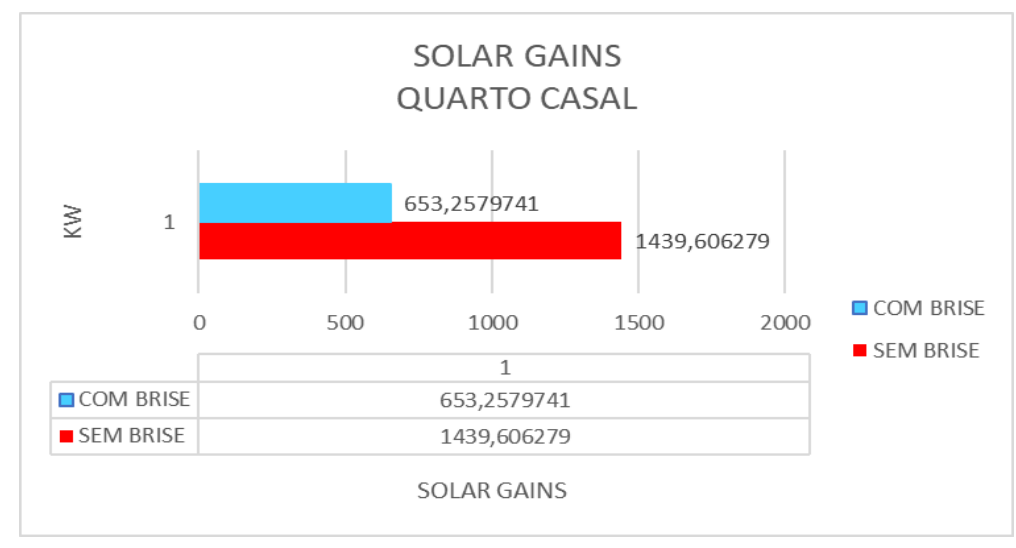

Fonte: Acervo do autor.

\subsection{Avaliação do conforto térmico.}

Índices de conforto térmico têm sido empregados para diversos propósitos, desde a determinação de limites de exposição humana às condições do meio, passando pela definição de conforto térmico em ambientes residenciais e comerciais; ou a indicação da melhor estratégia para reestabelecimento das condições de conforto, até a classificação climática (AULICIEMS; SZOKOLAY, 2007).

Humphreys (1978) observou que o centro da zona de conforto poderia ser determinado a partir da temperatura ambiente mais frequentemente apontada como o confortável, determinando, assim, uma temperatura neutra.

A temperatura externa de referência é a única variável independente na equação para determinação da temperatura neutra utilizada nos modelos adaptativos. A temperatura média mensal foi o primeiro tipo de referência a ser utilizado. Uma vez que esse parâmetro se baseia na série histórica de temperaturas do ar de um local específico, ele representa um clima típico e é, portanto, relacionado à experiência e aclimatação dos ocupantes (FERRARI; ZANOTTO, 2012). Givoni (1992) explica que ambientes de edifícios naturalmente ventilados acompanham as variações do clima devido a uma maior integração com este. Portanto, os usuários tendem a aceitar uma maior variação diária do que em edificações condicionadas artificialmente.

\subsubsection{Total de graus-hora de resfriamento.}

O critério de avaliação indicado por RTQ - R (BRASIL, 2010) e o calculo dos graus-hora para resfriamento, sendo a temperatura base adotada e de $26^{\circ} \mathrm{C}$. Assim, após a realização da simulação, todas as horas com temperatura operativa acima de $26^{\circ} \mathrm{C}$ nos ambientes de permanência prolongada são somadas e, através da equação a seguir, é calculado o indicador de graus hora para resfriamento.

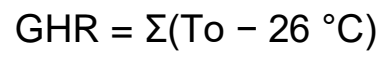

Onde:

GHR e o indicado de graus-hora para resfriamento

To e a temperatura operativa

O parâmetro "graus-hora" é determinado como a somatória da diferença da temperatura horária, quando esta se encontra superior a temperatura de base, no caso de resfriamento; 


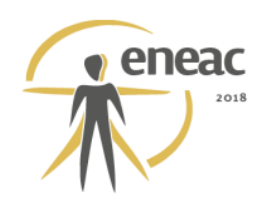

ou inferior a temperatura de base, para graus-hora de aquecimento. Uma demonstração desse parâmetro é apresentada na figura a seguir, onde a área pintada em verde acima da linha de temperatura de $26^{\circ} \mathrm{C}$, representa a quantidade de graus-hora de resfriamento e a área pintada em vermelho, abaixo da linha de temperatura de $18^{\circ} \mathrm{C}$, representa a quantidade de graus-hora de aquecimento.

\subsubsection{Total de horas em conforto - índice ASHRAE (2004)}

Durante a década de 1990 a ASHRAE direcionou um projeto de pesquisa específico que coletou dados de diferentes estudos de campo ao redor do mundo sobre conforto térmico (DEAR; BRAGER; COOPER, 1997). O resultado foi o projeto que culminou na revisão das normas até então vigentes.

Com base nas informações coletadas nessas pesquisas e utilizando a regressão linear formulou-se a seguinte equação para prever a temperatura neutra (Tn) em função da temperatura externa (Te):

$\mathrm{Tn}=0,31 \times \mathrm{T} \_\mathrm{e}+17,8$

Onde:

Tn é a temperatura neutra;

Te é a temperatura média exterior do mês avaliado

A equação resultante deste estudo foi incorporada à última versão da norma ASHRAE 55 (2004) para avaliação de das condições térmicas em ambientes internos com as seguintes limitações:

Para o intervalo de temperatura entre $10^{\circ} \mathrm{C}$ e $33,5^{\circ} \mathrm{C}$;

No caso de edifícios onde os ocupantes podem operar diretamente aberturas;

Para atividades com baixas taxas metabólicas (<1,3 MET).

Faixas de temperatura aceitáveis em edifícios naturalmente ventilados foram especificadas como $\pm 3,5$ para $80 \%$ do total e $\pm 2,5$ para $90 \%$ de aceitação geral.

O desempenho térmico de cada ambiente é avaliado em termos do total de horas dentro da zona de conforto segundo o índice de De Dear \& Brager (1998), com limites definidos como 2,5 graus a mais e a menos da temperatura operativa

A temperatura operativa foi calculada como sendo o valor médio entre a temperatura do ar e a temperatura radiante média.

\subsubsection{Total de horas em conforto nos ambientes, com brise.}

Figura 16: Gráfico comparativo de horas de conforto no quarto dos filhos, com brise. 


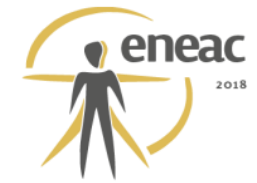

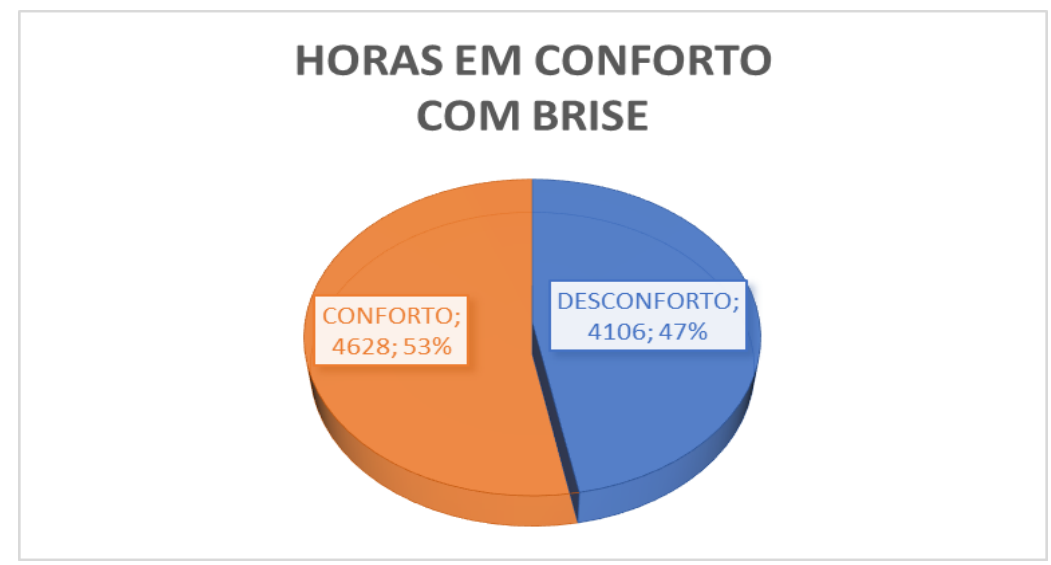

Fonte: Acervo do autor.

Com o auxílio do Excel para a análise e confecção deste gráficos, é clara a melhoria ocasionada pela implementação de brises simples na edificação, no caso desta simulação, foi somente levada em consideração elementos de proteção solar das esquadrias, entretanto, o Designbuilding é uma ferramenta que permite implementar qualquer tipo de revestimento em paredes, forros e telhados. Portanto, de posse destes gráficos é possível perceber que é imprescindível o uso de brises nesta casa em questão.

\section{CONCLUSÃO}

As simulações realizadas pelos programas utilizados neste trabalho levaram em consideração somente a ventilação leste, foi designado a velocidade do vento a 10 metros por segundo, logo, sendo uma limitação da ferramenta utilizada, o Flowdesign, o que na realidade necessitaria de mais simulações, pois, apesar do sentido dominante do vento nesta latitude de aproximadamente 3 graus seja leste, ainda existe os ventos sudeste e sul. Já no programa designbuilding as limitações foram de hardware, quanto mais dados fossem alocados na simulação mais tempo demoraria, portanto, mesmo com dados simplificados, os resultados obtidos foram satisfatórios.

Dessa forma, após horas de modelagem e análise de dados, é clara a dificuldade inerente de tentar simular a realidade de maneira a vender uma modificação a fim de aperfeiçoá-la. $O$ uso de diversos programas é bastante exaustivo, pois traz a necessidade de um arcabouço de habilidades que até então não os autores não possuíam, sendo, entretanto, bastante produtivo, pois os dados mostram um desenvolvimento positivo das modificações eleitas para a habitação de interesse social.

Todos os programas pelos quais a modelagem da casa passou, foram necessários para os resultados finais da última simulação, a qual mostrou graficamente e estatisticamente a melhoria de $1 \%$ a $4 \%$ de melhoria no conforto por calor no prédio e ainda reduzindo para mais da metade o ganho por radiação solar direta.

\section{REFERÊNCIAS BIBLIOGRÁFICAS}

ASSOCIAÇÃO BRASILEIRA DE NORMAS TÉCNICAS (ABNT). NBR 15220 - 3: desempenho térmico de edificações residenciais. Parte 3 - Zoneamento bioclimático brasileiro e diretrizes construtivas para habitações unifamiliares de interesse social. Rio de Janeiro, ABNT, 2005.

ASSOCIAÇÃO BRASILEIRA DE NORMAS TÉCNICAS (ABNT). NBR 15575: desempenho de edifícios residenciais até cinco pavimentos. Rio de Janeiro, ABNT, 2013.

AULICIEMS, A.; SZOKOLAY, S. Thermal comfort. PLEA note 3. PLEA International/ University of 
Queensland. 2 ed. 2007.

BRASIL. Regulamento Técnico da Qualidade para o nível de eficiência energética de Edificações Residenciais - RTQ-R. INMETRO - Instituto Nacional de Metrologia, Rio de Janeiro, 2012.

DEAR, R. J., BRAGER, G. S.; COOPER, D. ASHRAE RP-884 Final Report: developing an adaptive model of thermal comfort and preference. Atlanta: American Society of Heating, Refrigerating and Air-Conditioning Engineers; 1997.

FERRARI, S.; ZANOTTO, V. Adaptive comfort: Analysis and application of the main indices. Building and Environment 49: 25-32, 2012.

GIVONI, B. Comfort, climate analysis and building design guidelines. Energy and Buildings, 18, 1992.

OLESEN, B. W. The philosophy behind EN15251: Indoor environmental criteria for design and calculation of energy performance of buildings. Energy and Buildings 39: 740 - 749, 2007. 